\title{
A CONTABILIDADE E O HIPERTEXTO: UM ESTUDO SOBRE O USO DE WEBSITES COMO MEIO DE DISSEMINAÇÃO CIENTÍFICA CONTÁBIL POR INSTITUIÇÕES DE ENSINO SUPERIOR BRASILEIRAS*
}

\section{ACCOUNTING AND HYPERTEXT: A STUDY ON THE WEBSITES USE AS A MEANS OF DISSEMINATING SCIENTIFIC ACCOUNTING BY BRAZILIAN POSTSECONDARY EDUCATION INSTITUTIONS}

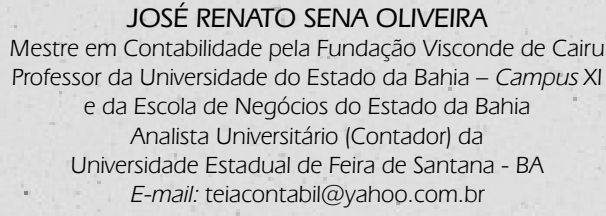

JOSÉ RENATO SENA OLIVEIRA

Mestre em Contabilidade pela Fundação Visconde de Cairu Professor da Universidade do Estado da Bahia - Campus X e da Escola de Negócios do Estado da Bahia Analista Universitário (Contador) da Universidade Estadual de Feira de Santana - BA E-mail: teiacontabil@yahoo.com.br

\author{
ANTONIO LOPO MARTINEZ \\ Professor Adjunto I do Departamento de Ciências Contábeis \\ da Faculdade de Ciências Contábeis \\ da Universidade Federal da Bahia \\ E-mail: antoniolopo@terra.com.br
}

\section{RESUMO}

Este estudo buscou investigar como as Instituições de Ensino Superior (IES) brasileiras utilizam os Websites institucionais para disseminar a produção acadêmico-científica da área contábil. Foi realizado um estudo com IES que oferecem o curso de graduação em Ciências Contábeis e que se submeteram ao Exame Nacional de Cursos (ENC) 2003. O universo de pesquisa compreendeu 461 cursos que se submeteram ao ENC. A amostra foi composta pelos cursos que obtiveram conceitos $\mathrm{A}, \mathrm{B}$ ou $\mathrm{C}$ (médios ou superiores à média) no referido exame, totalizando 303 cursos. A metodologia utilizada foi o estudo empírico-exploratório. Foram efetuados 5.711 registros referentes à produção científica. Concluiu-se que a maneira como as IES pesquisadas utilizam os Websites pode ser considerada tímida, uma vez que um elevado número de Instituições não utiliza os sites como meio de disseminação do conhecimento e as evidências apresentaram forte concentração sob os diversos parâmetros analisados: região geográfica, unidade federativa e conceito no ENC 2003.

Palavras-chave: Contabilidade; Contabilidade - Pesquisa Científica; Contabilidade - Internet.

\section{ABSTRACT}

The present study investigated how the institutional Websites are being used by the Brazilian schools (heretofore "IES") for disseminating accounting academic-scientific knowledge. A research was carried out with those IESs, which offer the undergraduate program in Accounting and were submitted to the National Exam of Educational Programs (ENC) 2003, coordinated by the Ministry of Education. The total research - includes 461 programs in Accounting offered in Brazil that were submitted to the ENC. The sample was composed of the 303 programs graded A, B or C (medium or superior to the average) in the above mentioned Exam. The methodology used was an empiric-exploratory study. - There were 5.711 entries referring to scientific knowledge. The use of Websites by the analyzed IESs can be considered incipient given the high number of institutions that - do not have sites as a way of disseminating - knowledge and the evidences showed strong concentration - according to a few parameters, such as geographical area, States of the Brazilian federation and grades obtained at ENC 2003.

Keywords: Accounting; Accounting - Scientific research; Accounting - Internet. 


\section{INTRODUÇÃO}

A Internet é uma rede mundial de computadores, compreendida como uma teia de informações que atinge considerável parcela da humanidade, com papel preponderante de meio de propagação de informação e conhecimento em diversas áreas. São cerca de 400 bilhões de páginas, segundo estimativas apresentadas no livro The Invisible Web (A Internet Invisível) do americano Chris Sherman, citado pela edição de 24/11/2004 da Revista Veja, no artigo intitulado "A Guerra dos Buscadores" (MARTHE, 2004). Segundo o mesmo artigo, estima-se que surgem todos os dias cerca de 7 milhões de novas páginas na Web. Essas páginas, desenvolvidas com a utilização do hipertexto, estão disponíveis em vários idiomas, informam e transmitem conhecimento e são acessadas dos mais distantes pontos do mundo.

A principal ferramenta informativa da web é o site, também denominado website, o qual se traduz como um conjunto de páginas com interfaces interativas e de fácil navegação, que permitem disponibilizar on-line uma infinidade de informações. A essas páginas são atribuídos endereços virtuais específicos que proporcionam acesso ao conteúdo a partir de qualquer computador conectado à rede.

A Internet, mesmo tendo um considerável poder de comunicação, ainda não é utilizada de forma satisfatória entre os acadêmicos da área contábil. Ao se buscarem alternativas que possam minimizar esse problema, um dos desafios é mostrar para o meio acadêmico contábil que a Internet pode ser útil para construir e disseminar o conhecimento e para desenvolver a própria ciência. Os estudiosos da contabilidade necessitam de páginas que tragam informações úteis, de forma clara e que atendam às suas necessidades, independentemente do seu campo de atuação. Partindo desse entendimento, o problema de pesquisa é, assim, apresentado: Como as Instituições de Ensino Superior brasileiras utilizam os Websites institucio-

\section{nais para disseminar a produção acadêmico-cientí- fica da área contábil?}

O estudo apresenta dois objetivos assim delineados:

- observar se as Instituições de Ensino Superior (IES) brasileiras que ministram o curso de Ciências Contábeis utilizam os Websites institucionais como canal de propagação do conhecimento acadêmicocientífico da área contábil;

- analisar como as iniciativas de disseminação do conhecimento oferecidas pela Internet estão contribuindo para o compartilhamento da produção acadêmico-científica contábil por meio dos sites institucionais das Instituições pesquisadas.

A hipótese do estudo foi a seguinte: os pesquisadores da área contábil das IES brasileiras exploram pouco a Internet para publicar suas pesquisas.

A pesquisa abordou a utilização da Internet como recurso tecnológico e sua aplicação na disseminação do conhecimento acadêmico-científico utilizado e produzido por pesquisadores da área contábil das IES do Brasil. O enfoque foi a utilização da Internet no meio acadêmico, a partir da disponibilização do conteúdo das pesquisas nos sites institucionais das Instituições que ministram o curso de Ciências Contábeis. O foco principal foi identificar aquelas que utilizam os sites institucionais para compartilharem o conhecimento científico da área contábil, independentemente da origem do conteúdo. Nesse sentido, são permitidas duplicidades de registro de uma mesma pesquisa, desde que estejam se referindo a diferentes endereços de Websites institucionais, mesmo que o(s) autor(es) do estudo não possua(m) qualquer vinculação com a IES que está compartilhando os trabalhos. Dessa forma, o enfoque foi na disseminação e não na autoria.

\section{REFERENCIAL TEÓRICO}

\subsection{O ambiente da Internet}

O ambiente da Web caracteriza-se por uma infinidade de páginas e uma diversidade de recursos que tornam o espaço virtual criado a partir da cibernética, denominado ciberespaço, um meio propício a uma interatividade crescente, com possibilidades das mais variadas. Na visão de Cohen (2000, p. 2), a Internet pode ser compreendida como a maior rede de computadores do mundo, uma rede de redes que provê acesso instantâneo para um mundo de informações e serviços. Para tanto, oferece um conjunto de ferramentas que possibilitam a realização de interações nesse ambiente. (LEÓN e DÍAZ, 2002).

Os recursos disponibilizados pela Internet oferecem um conjunto de ferramentas ou serviços que podem ser utilizados pelo usuário para as mais variadas finalidades, a exemplo das páginas Web (Websites), do e-mail, dos fóruns on-line (newsgroup), dos boletins on-line (newsletters), dos e-groups, chat, FTP, dos buscadores, entre outros (LAUDON e LAUDON, 1999; 2004).

No ambiente acadêmico-educacional, as Novas Tecnologias da Informação e Comunicação (NTIC) têm sido estudadas com o objetivo de criar novos métodos e usos dessas novas tecnologias como instrumentos do processo de aprendizagem e de formação educacional, bem como da transmissão de conhecimento. No meio acadêmico o ambiente da Internet está sendo utilizado como ferramenta colaborativa no processo de ensino-aprendizagem, independentemente da área de conhecimento, com a utilização dos diversos recursos disponibilizados para facilitar a transmissão de novas técnicas e novos conhecimentos. (DODGE, 2005). Alguns ramos do conhecimento já utilizam e discutem a utilização da tecnologia da informação 
para fins científicos, especialmente da Internet. (TEIXEIRA, 2001; AMARAL, 1997; BERNARDES, 2001).

Nesse sentido, Amaral (1997, p. 18) aponta três motivos pelos quais a Internet representa um potencial para as atividades de estudantes e professores: o primeiro é que a Web representa um imenso repositório de informações, que permite a disponibilidade de recursos on-line, ao qual qualquer indivíduo poderia ter acesso a informações, pessoas e idéias e pode também pesquisar profundamente em qualquer área do conhecimento, o que contribui nas tarefas de ensinar e aprender. Outro motivo é que cada autor teria a possibilidade de utilizar a infra-estrutura da rede para publicar seus trabalhos, oferecendo rapidez ao processo de criação, aplicação, análise dos resultados e aprimoramento das pesquisas. Por último, "em função da dinamicidade das relações que tomam forma através da rede, métodos modernos e criativos poderiam ser empregados para promover a educação fora da sala de aula".

Para Tajra (2002, p. 31), a Web é a "biblioteca universal, pois possui o maior acervo de informações no mundo e está disponível 24 horas por dia e em qualquer país" e, diante dessa amplitude, a preocupação no meio acadêmico passa a ser em função do "como" tratar a informação disponibilizada nesse espaço, ou seja, como tratá-la e analisá-la.

\subsection{O processo de comunicação científica por meios eletrônicos}

O processo de comunicação científica tem sido objeto de estudo da Ciência da Informação, que busca aprofundar o entendimento e o desenvolvimento de novos meios, com o objetivo de tornar acessível o conhecimento produzido pela comunidade acadêmica. Independentemente de qual das concepções de ciência cada pesquisador entenda como adequada, ou do caminho escolhido para chegar à verdade científica, Targino (2000, p. 51) destaca que "qualquer que seja a concepção que se adote para a ciência, é impossível negar o seu caráter evolutivo, mutável e dinâmico, que faz da pesquisa científica seu instrumento-mor e da comunicação científica seu elemento básico".

Sobre esse processo de comunicação científica, isto é, de propagação do conhecimento científico, Bueno (1984, p. 14) apresenta uma classificação em função da amplitude da difusão científica, caracterizando-a sob duas vertentes: a difusão para especialistas e a difusão para o público em geral. À primeira, o autor atribui a denominação de disseminação científica, que é "o processo de transferência de informações científicas e tecnológicas, transcritas em códigos especializados, a um público seleto, formado por especialistas" (BUENO, 1984, p. 15-16). À última, o autor chama de divulgação científica, que compreende "a utilização de recursos, técnicas e processos para a veiculação de informações científicas e tecnológicas ao público em geral" (BUENO, 1984, p. 18). No caso específico deste estudo, interessa a primeira vertente, uma vez que a comunicação científica em foco é a denominada pelo autor como disseminação científica, por ser voltada para os especialistas e para aqueles que formam a comunidade científica.
O papel dessas comunidades de especialistas, denominadas comunidade científica (conjunto de cientistas que partilham área de interesse comum em suas atividades de pesquisa), é produzir conhecimento científico, fazendo avançar a ciência, e compartilhar com os interessados, precipuamente pelos canais de divulgação característicos do meio acadêmico.

Mueller e Passos (2000, p. 17) destacam que "o formato tradicional do periódico científico, impresso em papel já começa a ser alvo de tentativas de inovação e mudanças. não apenas de canal, mas de concepção", pois compreendem que "volumes e fascículos poderiam ser abolidos para que se usufruísse da rapidez e da capacidade de interação dos meios eletrônicos". Nesse sentido, uma vantagem dos meios eletrônicos em comparação com os meios impressos para disseminar conhecimento está ligada à sua própria origem. A diferença entre a mídia impressa e a mídia eletrônica está na motivação principal: para a primeira foi o desejo do lucro, enquanto que na segunda foi o desenvolvimento da pesquisa. (MEADOWS, 2000). Também serve de referência na "socialização" do conhecimento entre pesquisadores que não têm acesso aos mesmos recursos (RUSSELL, 2000; ZAMBONI, 2001).

\subsection{A disseminação científica no ciberespaço}

León e Díaz (2002, p. 2) afirmam que os sites são a representação mais adequada do ciberespaço pois são estruturas de informação, como tantas outras, mas com características singulares proporcionadas pela hipertextualidade e por sua localização em um cenário diferente, de acesso múltiplo e massivo. De acordo com Monteiro (2003, p. 1), o virtual é o principal atributo do ciberespaço e também o que melhor o descreve. Isso porque o ciberespaço "dispõe o conhecimento e a informação em um espaço e estado contínuos de modificação, em função de sua plasticidade e fluidez, permitindo a interatividade e organizando o conhecimento". Nessa nova forma apresentada no ciberespaço, a organização do conhecimento se dá em "um novo tipo de escritura (...) só visualizada e possível ou mesmo inteligível a partir do hipertexto funcional".

Para Lévy (1996, p. 19), a principal característica da virtualização (tornar virtual) é o desprendimento do aqui e agora, pois "o virtual, com muita freqüência, 'não está presente'", configurando-se, portanto, como um aspecto de desterritorialização. No uso desse espaço desterritorializado virtual da Web na pesquisa científica, Blattmann e Fragoso (2003, p. 15) apontam que "o acesso à informação, o saber localizar, avaliar e usar a informação para interagir na sociedade está conduzindo a humanidade para um novo momento histórico - a era do conhecimento on-line".

Ao fazer um paralelo com a aplicação da pesquisa no campo profissional, defendida por Ziebart e Feller (2004). os quais afirmam que a aplicação da pesquisa na área profissional é um processo que compreende a identificação de um problema contábil e o desenvolvimento de uma solução usando a teoria ou a literatura profissional existente. 
essas mesmas etapas podem ser aplicadas à pesquisa acadêmica contábil na Internet, uma vez que, em ambos os casos, requerem do pesquisador habilidades que os tornem aptos a identificar uma questão ou demonstrar claramente o problema encontrado e serem capazes de identificar alternativas plausíveis para a resolução desse. Entretanto, conforme destacam Ziebart et al. (2001, p. 10), a Internet é um ambiente dinâmico, com freqüentes mudanças. Em decorrência dessa característica, as páginas são atualizadas, movidas ou desativadas e essa dinâmica às vezes pode exigir mudanças nas atividades de pesquisa, por frustrar as iniciativas do pesquisador.

Um documento elaborado no sentido de colaborar na disseminação do conhecimento em larga escala é a "Declaração de Berlim sobre Acesso Livre ao Conhecimento nas Ciências e Humanidades": trata-se de um acordo pelo qual os seus signatários comprometem-se a utilizar a Internet para colaborar na livre difusão do conhecimento. A Declaração de Berlim chama a atenção, também, para a necessidade dos signatários apoiarem a transição para o "Paradigma do Acesso Livre Eletrônico”. Nesse sentido, Rodrigues (2004) aponta que o livre acesso deve ser entendido como "a disponibilização livre na Internet de literatura de carácter académico ou científico, permitindo a qualquer utilizador ler, descarregar, copiar, distribuir, imprimir, pesquisar ou referenciar o texto integral dos documentos". Esses princípios podem, inclusive, trazer novas perspectivas para a disseminação livre do conhecimento acadêmico-científico contábil, como forma de compartilhar as pesquisas desenvolvidas e aprofundar o conhecimento da área por meio do avanço da pesquisa científica.

\section{METODOLOGIA}

Quanto ao nível da pesquisa, de acordo com Gil (1999, p. 43), tem caráter predominantemente exploratório, uma vez que as pesquisas desse tipo "são desenvolvidas com o objetivo de proporcionar visão geral (...) acerca de determinado fato"; além disso, neste tipo de estudo, as hipóteses não são estabelecidas de início e são construídas durante o desenvolvimento desta, ou seja, aplica-se no caso em que "o tema escolhido é pouco explorado e torna-se difícil sobre ele formular hipóteses precisas e operacionalizáveis".

De acordo com os tipos de amostragem não probabilística apresentados por Marconi e Lakatos (1999, p. 5360), a pesquisa é classificada como não probabilística por tipicidade, que, no entendimento de Ackoff apud Marconi e Lakatos (1999, p. 55), é feita a partir da escolha de um subgrupo típico em relação à população como um todo $e$ esse é utilizado como "barômetro" dessa; além disso, as observações se restringem ao subgrupo e "as conclusões obtidas são generalizadas para o total da população".

Para elaboração do referencial teórico foi utilizada a técnica de documentação indireta, com utilização de pesquisa bibliográfica e uso de fontes secundárias. A metodologia constou da divisão da pesquisa em duas fases, conforme descritas a seguir:

\subsection{Fase Exploratória Documental}

Nessa fase, o estudo apresentou delineamento de pesquisa documental, com utilização de técnicas de pesquisa baseadas em documentação indireta, cujos dados obtidos foram caracterizados como secundários de fontes primárias, conforme evidenciado no Quadro 10

Além do conceito obtido no ENC, as Instituições foram classificadas também quanto à localização geográfica (região geográfica, unidade federativa e cidade) e quanto à dependência administrativa (federal, estadual, municipal ou privada). Com a utilização dos dados secundários de fontes primárias fornecidos pelo INEP/MEC, estabeleceuse o universo da pesquisa, que compreendeu 461 (quatrocentos e sessenta e um) cursos de graduação em Ciências Contábeis que se submeteram ao ENC 2003 (BRASIL, 2003). Do total de cursos que participaram do ENC, 303 (trezentos e três) atenderam ao critério estabelecido para composição da amostra, sendo, portanto, o total de cursos seus componentes.

\section{Etapas da Fase Exploratória Documental do Estudo}

Coleta do resultado da edição 2003 do ENC, obtido por meio de um CD-ROM fornecido pela Diretoria de Estatísticas e Avaliação da Educação Superior do Instituto Nacional de Estudos e Pesquisas Educacionais Anísio Teixeira do Ministério da Educação (INEP/MEC), contendo os resultados das edições do ENC realizadas até 2003, distribuídos por Unidade Federativa, Instituição e Curso.

Seleção das IES que ministram o curso de Ciências Contábeis e que se submeteram à edição 2003 do ENC realizado pelo INEP/MEC, para a determinação do universo da pesquisa.

Seleção das IES que ministram o curso de Ciências Contábeis, tendo como critério a obtenção de conceito A, B ou C no ENC 2003, para comporem a amostra.

Catalogação dos endereços virtuais das IES que compõem a amostra a partir de um mecanismo de busca na Internet (<http://www. google.com.br>). 
A distribuição da amostra pode ser observada de acordo com a região geográfica do país, conforme Tabela $1 \mathbf{0}$.

\subsection{Fase Empírico-Exploratória}

Essa fase foi denominada de empírico-exploratória e delineou-se como estudo de campo, uma vez que, conforme Oliveira (1997, p. 124), consistiu na "observação dos fatos tal como ocorrem espontaneamente, na coleta de dados e no registro de variáveis presumivelmente para posteriores análises". É também empírica, por se tratar de um estudo que busca compreender a realidade. Para tanto, foi realizada cumprindo-se os procedimentos descritos no Quadro $2 \mathbf{0}$.

Para realizar a catalogação e registro das observações efetuadas utilizou-se o modelo apresentado por Colbert, Aldridge e Ross (2002), com adaptações que permitiram contemplar as ocorrências existentes nos sites das IES que compuseram a amostra. Tal estudo, intitulado "Using the internet to access accounting journals: improving research efficiency", trata da classificação de periódicos científicos americanos da área contábil disponibilizados através da Web a partir de três critérios: text full (artigos completos) abstracts (resumos dos artigos) e table of contents (sumário das edições).
Para efetuar o registro das visitas aos sites, foi desenvolvido um banco de dados utilizando o Microsoft Access $2003^{\circ}$, software de banco de dados do pacote Microsoft Office Professional $2003^{\odot}$ para Windows XP ${ }^{\odot}$. O banco de dados foi estruturado com tabelas paralelas, com relacionamento entre essas, nas quais foram armazenados os registros a partir do formulário principal do banco de dados. O formulário principal criado para registro das ocorrências no banco de dados apresenta um formulário de registro que contemplou os seguintes campos (variáveis do estudo), conforme o Quadro $3 \mathbf{0}$.

A segunda parte do formulário foi elaborada como um subformulário para cadastro das ocorrências de disseminação, o qual contemplou os campos (variáveis) do Quadro 40.

Os registros foram efetuados a partir de uma classificação/categorização prévia criada e pré-testada, que envolvem dois campos (variáveis): Tipo de Publicação e Tipo de Texto. Nesses campos, as ocorrências foram categorizadas nos tipos apresentados no Quadro 50.

Foram incluídos em ambos uma categoria denominada "Nenhum" para permitir o registro das IES que não apresentaram publicações no site. Os sites em manutenção ou

Tabela 1 \Distribuição dos Cursos de Ciências Contábeis por Região e por Conceito no Exame Nacional de Cursos, 2003

\begin{tabular}{l|c|c|c|c}
\multirow{2}{*}{ Região } & \multicolumn{3}{|c|}{ Conceito no ENC } & \multirow{2}{*}{ TOTAL } \\
\cline { 2 - 4 } Centro-Oeste & A & B & C & \\
\hline Nordeste & 6 & 4 & 19 & 29 \\
\hline Norte & 12 & 8 & 23 & 43 \\
\hline Sudeste & 23 & 5 & 8 & 15 \\
\hline Sul & 30 & 16 & 40 & 79 \\
\hline TOTAL & 73 & 24 & 83 & 137 \\
\hline
\end{tabular}

Fonte: Resultado Geral do Exame Nacional de Cursos 2003 (BRASIL, 2003)

\section{Etapas da Fase Empírico-Exploratória do Estudo}

Elaboração de um banco de dados para possibilitar o registro das ocorrências de disseminação das pesquisas encontradas nos sites das IES. Os dados iniciais armazenados no banco de dados foram os dados das Instituições obtidos na fase exploratória documental.

Pesquisa on-line, por meio de visitas aos sites das IES que compõem a amostra, onde se registrou as ocorrências de disseminação do conhecimento acadêmico-científico contábil a partir de critérios estabelecidos com a adaptação do modelo escolhido. Tal procedimento teve como finalidade permitir traçar um perfil sobre a utilização do ambiente da Internet para a disseminação científica por meio de Websites pelos componentes da amostra.

Quadro 2 Etapas da Fase Empírico-Exploratória do Estudo, 2004

Variáveis da Primeira Parte do Formulário de Registro das Ocorrências

Região (compreendendo as regiões político-geográficas do Brasil: Centro-Oeste (CO), Norte (N), Nordeste (NE), Sul (S) e Sudeste (SE)) Unidade Federativa (Estados e Distrito Federal)

Nome completo da Instituição e cidade onde está localizada a Unidade objeto de análise (no caso da existência de campi)

Dependência Administrativa (Estadual, Federal, Municipal ou Privada)

Endereço do site principal da IES

Quadro 3 Variáveis que compõem a primeira parte do formulário de registro das ocorrências, 2004 
Variáveis da Segunda Parte do Formulário de Registro das Ocorrências

Tipo de Publicação

Tipo de Texto

Título do Trabalho

Endereço do site onde foi encontrada a referência ao trabalho

Campos para registro dos nomes dos autores (limitados a 04 autores)

Data da visita ao site

Observação

Quadro 4 Variáveis que compõem a segunda parte do formulário de registro das ocorrências, 2004

\begin{tabular}{|c|c|}
\hline Tipo de Publicação & Tipo de Texto \\
\hline Anais & Referência \\
\hline Apostila & Resumo \\
\hline Artigo na web & Texto Completo \\
\hline Capítulo de livro & \\
\hline Dissertação & \\
\hline Livro & \\
\hline Monografia & \\
\hline Periódico & \\
\hline Projeto de Pesquisa & \\
\hline Tese & \\
\hline
\end{tabular}

Quadro 5 Categorias que compõem o campo Tipo de Publicação, 2004

fora de serviço foram visitados em datas diferentes, as visitas relatadas no campo Observação e os campos Tipo de Publicação e Tipo de Texto categorizados como "Nenhum" nos casos de insucesso em ambas. A pesquisa limitou- se ao conteúdo apresentado em endereços do domínio da Instituição e foram descartadas as páginas hospedadas em outros domínios.

\section{RESULTADOS E DISCUSSÃO}

Para verificar a ocorrência de disseminação de pesquisas contábeis por meio de Websites, realizou-se uma pesquisa empírico-exploratória, através da qual foram coletados dados primários a partir dos sites institucionais das IES que atenderam à delimitação estabelecida para o estudo. As visitas aos sites tiveram como finalidade proceder à catalogação das pesquisas e foram realizadas entre 10 de setembro e 26 de outubro de 2004.

Os dados apresentados nas tabelas foram obtidos por meio da filtragem dos registros do banco de dados com o uso do Relatório de Tabela Dinâmica do Microsoft Excel 2003 para Windows XP® ${ }^{\odot}$, por meio de referência cruzada das variáveis. Como os dados foram registrados direta- mente no banco de dados, não houve fase de tabulação. Ao todo, foram efetuados 5.924 (cinco mil, novecentos e vinte e quatro) registros. Ao se desconsiderarem 213 (duzentos e treze) registros referentes às IES que não apresentaram publicações, o número de ocorrências analisadas passa a corresponder a 5.711 (cinco mil, setecentos e onze) registros.

O primeiro aspecto observado foi a distribuição das IES quanto à ocorrência de disseminação de produção científica contábil no site institucional, com destaque para o número de IES que não apresentaram ocorrências de produção nos Websites, o qual equivale a 213 Instituições já mencionadas, como se verifica na Tabela $2 \mathbf{O}$ a seguir:

Tabela 2 - Distribuição das IES pesquisadas de acordo com a ocorrência de disseminação de produção científica contábil por meio de Websites, 2004

\begin{tabular}{l|c|c}
\multicolumn{1}{c|}{ Situação } & Ocorrências & Percentual \\
Publica & 90 & 29,70 \\
\hline Não publica & 213 & 70,30 \\
\hline TOTAL & 303 & 100,00
\end{tabular}


Esse comparativo destaca o elevado percentual de Instituições que não apresentaram ocorrências de publicação nos sites, o qual representa mais de 70\% (setenta por cento) das IES pesquisadas, ou seja, superior a dois terços.

Os valores apresentados a partir desse ponto contemplam apenas os 5.711 registros comentados, os quais compreendem as 90 (noventa) IES que apresentaram tais ocorrências.

A distribuição, a seguir, diz respeito às ocorrências de acordo com o Tipo de Publicação. Destacam-se as ocorrências de disseminação de Monografia, com 1.427 (hum mil, quatrocentos e vinte e sete) registros, seguidas de Dissertação com 1.257 (hum mil, duzentos e cinqüenta e sete), de Anais, com 1.182 (hum mil, cento e oitenta e dois) e de Periódico, com 1.063 (hum mil e sessenta e três) registros, como se verifica na Tabela $3 \mathbf{0}$.

O tipo de ocorrência mais freqüente foi Monografia, que representou cerca de um quarto de toda a produção científica encontrada. Isso reflete o fato de se tratar do tipo de produção mais comum entre as Instituições, uma vez que são produzidas por concluintes dos cursos de graduação em diversas IES como Trabalhos de Conclusão de Curso (TCC). Destacou-se ainda a Dissertação, com 1.257 (hum mil, duzentas e cinqüenta e sete) ocorrências. Embora existam registros repetidos desse tipo de publicação, esses não foram excluídos, pois o estudo não visou identificar as publicações por instituição de origem, mas pelas evidências de disseminação independentemente de possíveis duplicidades, ou seja, o estudo permite duplicidade de registro se um mesmo trabalho for citado por mais de uma IES.

Um fator que contribuiu para o elevado número da categoria Dissertação como Tipo de Publicação foi o acesso à pesquisa "PeCont - A Pesquisa Acadêmica Contábil no Brasil", de autoria de Riccio e Sakata (2003), disponibilizada no site do Laboratório de Tecnologia e Sistemas de Informação da Faculdade de Economia, Administração e Contabilidade da Universidade de São Paulo (FEA/USP) (<http://www.tecsi.fea.usp.br/producao/>), que permitiu acesso ao cadastro de teses e dissertações defendidas nos programas de pós-graduação stricto sensu da área contábil, reconhecidos pela Coordenação de Aperfeiçoamento de Pessoal de Ensino Superior (CAPES), órgão do Ministério da Educação responsável pela avaliação dos programas de pós-graduação dessa modalidade oferecidos pelas IES brasileiras. O estudo possui atualização periódica, com dados obtidos semestralmente junto às secretarias dos programas e contempla dissertações e teses defendidas nesses desde 1962.

Quanto ao número de ocorrências de disseminação de Anais como Tipo de Publicação, destacaram-se os registros de duas Instituições em particular: Universidade Federal de Pernambuco (UFPE) e USP-São Paulo. A UFPE apresentou 509 (quinhentos e nove) registros, por conta de um serviço denominado Repositório de Trabalhos disponibilizado no site do Departamento de Ciências Contábeis. Nesse espaço do Website encontram-se textos integrais dos trabalhos apresentados no XVI Congresso Brasileiro de Contabilidade e nas edições III, V e VI do Congresso de Gestão Estratégica de Custos, denominado posteriormente de Congresso Brasileiro de Custos, com um total de 318 (trezentos e dezoito) trabalhos em texto completo. Além disso, outro espaço no site da IES oferece um serviço de consulta de referências da produção científica dos docentes do Departamento.

A segunda IES que se destacou foi a USP, Campus da Capital, com um total de 434 (quatrocentos e trinta e quatro) registros, dos quais 322 (trezentos e vinte e dois) em texto completo, referentes aos eventos realizados na FEA/ USP, quais sejam as edições I, II e III do Congresso USP de Controladoria e Contabilidade e do VI Congresso Brasileiro de Custos.

Após a apresentação da distribuição das ocorrências de acordo com o Tipo de Publicação, foi possível observar, ainda, como se distribuem tais ocorrências por outro critério, com base no Tipo de Texto, demonstrado na Tabela 40.

Nas ocorrências de disseminação por Tipo de Texto apresentadas na Tabela 4, destacou-se a Referência, com 3.153 registros, equivalente a cerca de 55\% (cinqüenta e cinco por

Tabela 3 Distribuição das ocorrências de disseminação de produção científica contábil por Tipo de Publicação, 2004

\begin{tabular}{|c|c|c|c|c|c|c|c|}
\hline \multirow{2}{*}{ Tipo de Publicação } & \multicolumn{6}{|c|}{ Tipo de Texto } & \multirow{2}{*}{$\begin{array}{c}\text { Total de } \\
\text { Ocorrências }\end{array}$} \\
\hline & Referências & $\%$ & Resumo & $\%$ & Texto completo & $\%$ & \\
\hline Anais & 460 & 38,92 & 54 & 4,57 & 668 & 56,51 & 1.182 \\
\hline Apostila & 3 & 9,68 & 0 & 0,00 & 28 & 90,32 & 31 \\
\hline Artigo na web & 89 & 33,21 & 25 & 9,33 & 154 & 57,46 & 268 \\
\hline Capítulo de livro & 13 & 76,47 & 0 & 0,00 & 4 & 23,53 & 17 \\
\hline Dissertação & 986 & 78,44 & 208 & 16,55 & 63 & 5,01 & 1.257 \\
\hline Livro & 48 & 36,92 & 82 & 63,08 & 0 & 0,00 & 130 \\
\hline Monografia & 679 & 47,58 & 743 & 52,07 & 5 & 0,35 & 1.427 \\
\hline Periódico & 552 & 51,93 & 192 & 18,06 & 319 & 30,01 & 1.063 \\
\hline Projeto de Pesquisa & 36 & 75,00 & 12 & 25,00 & 0 & 0,00 & 48 \\
\hline Tese & 287 & 99,65 & 1 & 0,35 & 0 & 0,00 & 288 \\
\hline TOTAL & 3.153 & & 1.317 & & 1.241 & & 5.711 \\
\hline
\end{tabular}


Tabela 4 Distribuição das ocorrências de disseminação de produção científica contábil por Tipo de Texto, 2004

\begin{tabular}{l|c|c} 
Tipo de Texto & Ocorrências & Percentual \\
Referência & 3.153 & 55,21 \\
Resumo & 1.317 & 23,06 \\
Texto completo & 1.241 & 21,73 \\
\hline TOTAL & 5.711 & 100,00
\end{tabular}

cento) do total de registros efetuados. Isso denota que ainda é necessário melhorar o tipo de texto de tais ocorrências, uma vez que, embora representem uma forma de disseminar conhecimento, é a categoria mais limitada dentre as três utilizadas para classificação, por reduzir-se a três pontos básicos: título do trabalho, autor(es) e meio de publicação. Verificou-se, também informações incompletas nos registros desse tipo de texto; com referência a trabalhos publicados em anais de eventos, por exemplo, não eram informados detalhes importantes para se obter o texto completo, tais como local, ano e instituição promotora.

O primeiro cruzamento de referências efetuado diz respeito à incidência de disseminação ao comparar as variáveis Tipo de Publicação e Região. Destacou-se nesse o número de registros da Região Sudeste, com 2.758 (dois mil, setecentos e cinqüenta e oito), da Região Sul, com 1.730 (hum mil, setecentos e trinta) registros e da Região Nordeste, com 1.141 (hum mil, cento e quarenta e um) registros, conforme apresentado na Tabela $5 \boldsymbol{\nabla}$.

No que tange aos dados apresentados no cruzamento das variáveis Tipo de Publicação e Região, observou-se que há concentração dos registros de disseminação em determinadas regiões geográficas do país, principalmente Sudeste, Sul e Nordeste, nessa ordem.

Outro comparativo é feito a seguir, a partir das variáveis Tipo de Publicação e UF, no qual se observa o destaque do Estado de São Paulo, com 2.255 (dois mil, duzentos e cinqüenta e cinco) registros, seguido de Pernambuco, com 1.053 (hum mil e cinqüenta e três) e de Santa Catarina, com 748 (setecentos e quarenta e oito) registros, como se observa na Tabela 60

A concentração pode ser verificada, também, na distribuição por Unidade Federativa apresentada na Tabela 6 , na qual se observa que de 27 (vinte e sete) UF existentes no país, apenas 13 (treze) apresentaram registros de disseminação, prevalecendo a concentração em algumas UF deste grupo, notadamente São Paulo, Pernambuco e Santa Catarina, cuja soma dos percentuais obtidos por essas três superam $73 \%$ (setenta e três por cento) do total de registros de disseminação de produção científica contábil efetuados.

O comparativo, a seguir, confronta as variáveis Tipo de Publicação versus Dependência Administrativa. Evidenciou que as IES federais são as que apresentam maior volume de ocorrências, com 2.270 (dois mil, duzentos e setenta) registros, seguidas das Estaduais, com 2.206 (dois mil, duzentos e seis) registros, como se observa na Tabela $7 \boldsymbol{\theta}$

No cruzamento das variáveis Tipo de Publicação e Dependência Administrativa, observou-se que as categorias Estadual e Federal apresentaram números de ocorrências semelhantes, com aproximadamente 39\% (trinta e nove por cento) do total de registros para cada categoria. Evidenciou, também, uma distribuição diversificada das ocorrências de disseminação de produção nessas duas categorias de dependência administrativa, embora se destaquem alguns tipos de publicação, notadamente Dissertação, no caso da Estadual e de Anais e Monografia, no caso da Federal. Observou-se, ainda, que as Instituições cuja depen-

Tabela 5 Distribuição das ocorrências de disseminação de produção científica contábil por Tipo de Publicação e por Região, 2004

\begin{tabular}{|c|c|c|c|c|c|c|}
\hline \multirow{2}{*}{ Tipo de Trabalho } & \multicolumn{5}{|c|}{ Região } & \multirow{2}{*}{ Total } \\
\hline & $\mathrm{CO}$ & $\mathbf{N}$ & NE & $\mathbf{S}$ & SE & \\
\hline Anais & 14 & 0 & 527 & 124 & 517 & 1.182 \\
\hline Apostila & 1 & 0 & 3 & 21 & 6 & 31 \\
\hline Artigo na web & 23 & 0 & 69 & 4 & 172 & 268 \\
\hline Capítulo de livro & 0 & 0 & 8 & 6 & 3 & 17 \\
\hline Dissertação & 33 & 0 & 304 & 50 & 870 & 1.257 \\
\hline Livro & 8 & 0 & 11 & 15 & 96 & 130 \\
\hline Monografia & 0 & 0 & 77 & 1.025 & 325 & 1.427 \\
\hline Periódico & 3 & 0 & 6 & 451 & 603 & 1.063 \\
\hline Projeto de Pesquisa & 0 & 0 & 1 & 33 & 14 & 48 \\
\hline Tese & 0 & 0 & 135 & 1 & 152 & 288 \\
\hline TOTAL & 82 & 0 & 1.141 & 1.730 & 2.758 & 5.711 \\
\hline
\end{tabular}


Tabela 6 Distribuição das ocorrências de disseminação de produção científica contábil por Tipo de Publicação e por UF, 2004

\begin{tabular}{|c|c|c|c|c|c|c|c|c|c|c|c|c|c|c|}
\hline \multirow{2}{*}{ Tipo de Publicação } & \multicolumn{13}{|c|}{ UF } & \multirow{2}{*}{ Total } \\
\hline & BA & CE & DF & MG & MS & MT & PE & PR & RJ & RN & RS & SC & SP & \\
\hline Anais & 18 & 0 & 6 & 23 & 8 & 0 & 509 & 30 & 13 & 0 & 16 & 78 & 481 & 1.182 \\
\hline Apostila & 3 & 0 & 0 & 1 & 1 & 0 & 0 & 0 & 0 & 0 & 18 & 3 & 5 & 31 \\
\hline Artigo na web & 10 & 0 & 0 & 34 & 0 & 23 & 59 & 0 & 55 & 0 & 1 & 3 & 83 & 268 \\
\hline Capítulo de livro & 0 & 0 & 0 & 0 & 0 & 0 & 8 & 5 & 0 & 0 & 0 & 1 & 3 & 17 \\
\hline Dissertação & 0 & 0 & 33 & 0 & 0 & 0 & 271 & 7 & 129 & 33 & 43 & 0 & 804 & 1.257 \\
\hline Livro & 1 & 0 & 8 & 0 & 0 & 0 & 10 & 7 & 2 & 0 & 7 & 1 & 94 & 130 \\
\hline Monografia & 16 & 0 & 0 & 0 & 0 & 0 & 61 & 79 & 1 & 0 & 337 & 609 & 324 & 1.427 \\
\hline Periódico & 5 & 1 & 1 & 229 & 2 & 0 & 0 & 199 & 8 & 0 & 207 & 45 & 366 & 1.063 \\
\hline Projeto de Pesquisa & 1 & 0 & 0 & 8 & 0 & 0 & 0 & 17 & 0 & 0 & 8 & 8 & 6 & 48 \\
\hline Tese & 0 & 0 & 0 & 0 & 0 & 0 & 135 & 1 & 0 & 0 & 0 & 0 & 152 & 288 \\
\hline TOTAL & 54 & 1 & 48 & 295 & 11 & 23 & 1.053 & 345 & 208 & 33 & 637 & 748 & 2.255 & 5.711 \\
\hline
\end{tabular}

Tabela 7 Distribuição das ocorrências de disseminação de produção científica contábil por Tipo de Publicação e por Dependência Administrativa, 2004

\begin{tabular}{l|r|r|r|r|r}
\multirow{2}{*}{ Tipo de Publicação } & \multicolumn{4}{|c|}{ Dependência Administrativa } & \multicolumn{2}{c}{ Total } \\
\cline { 2 - 5 } Anais & Estadual & Federal & Municipal & Privada & 1.182 \\
Apostila & 508 & 659 & 0 & 15 & 31 \\
Artigo na web & 2 & 1 & 0 & 28 & 268 \\
Capítulo de livro & 75 & 77 & 0 & 116 & 17 \\
Dissertação & 3 & 10 & 0 & 119 & 1.257 \\
Livro & 794 & 344 & 0 & 10 & 130 \\
Monografia & 98 & 22 & 0 & 668 & 1.427 \\
Periódico & 87 & 672 & 0 & 263 & 1.063 \\
Projeto de Pesquisa & 466 & 332 & 2 & 0 & 48 \\
Tese & 21 & 17 & 0 & 0 & 288 \\
\hline TOTAL & 152 & 136 & 0 & 1.233 & 5.711 \\
\hline PERCENTUAIS & 2.206 & 2.270 & 2 & $21,59 \%$ & $100,00 \%$
\end{tabular}

dência administrativa é Municipal apresentaram número extremamente reduzido de ocorrências, não conseguindo atingir $1 \%$ (um por cento) do total de registros.

Os percentuais apresentados destacam que o tipo de Instituição cuja dependência administrativa é Federal obteve aproximadamente $40 \%$ (quarenta por cento) dos registros das ocorrências, seguido do Estadual, com cerca de 39\% (trinta e nove por cento), e do tipo Privada, com cerca de $22 \%$ (vinte e dois por cento). Outro fato a ser considerado é o percentual obtido pelas IES do tipo Municipal, que não chegam a atingir $1 \%$ (um por cento) do total de registros.

Nesse cruzamento de variáveis, observou-se que as IES públicas (Estadual, Federal e Municipal) detêm a maioria absoluta das ocorrências de disseminação da produção científica. A soma dessas categorias alcança cerca de 78\% (setenta e oito por cento) do total de registros.

A Tabela $8 \bigcirc$ comparou os números de ocorrências de disseminação com o número de cursos, ambos distribuídos por conceito no ENC e apresentou a média aritmética. O comparativo evidenciou que o Conceito $A$ apresenta a maior média, com aproximadamente 60 (sessenta) regis- tros por IES, seguido do Conceito B, com valor próximo de 9 (nove) registros por Instituição. Ressalte-se que a média aritmética da soma de ocorrências e de cursos apresenta um valor médio de aproximadamente 19 (dezenove) registros por Instituição.

Esse comparativo demonstra uma predominância dos registros nos cursos de Conceito $A$, cujo número de ocorrências das IES que possuem esse conceito representa mais de $76 \%$ (setenta e seis por cento) de toda a produção registrada. Outro comparativo importante é a média aritmética dos resultados, no qual se destaca a média das Instituições com Conceito $A$, com aproximadamente 60 (sessenta) registros por IES. Observou-se, também, que, embora o número absoluto de ocorrências seja inferior nas Instituições com Conceito $B$ em relação ao Conceito $C$, a média daquelas é próxima ao dobro de ocorrências em relação à média obtida por essas. Isso confirma a classificação das IES a partir dos critérios apresentados pelo ENC quanto à qualidade do curso, ou seja, os cursos que possuem conceitos superiores no ENC apresentaram maior volume de ocorrências de disseminação da produção científica contábil. 
Tabela 8 Valores médios da distribuição das ocorrências de disseminação de produção científica contábil por Conceito no ENC, 2004

\begin{tabular}{|c|c|c|c|c|}
\hline \multirow{2}{*}{ Descrição } & \multicolumn{3}{|c|}{ Conceito no ENC } & \multirow{2}{*}{ Total } \\
\hline & A & B & C & \\
\hline Número de ocorrências & 4.370 & 496 & 845 & 5.711 \\
\hline Número de cursos & 73 & 57 & 173 & 303 \\
\hline VALORES MÉDIOS & 59,86 & 8,70 & 4,88 & 18,85 \\
\hline
\end{tabular}

Também se apresentou um comparativo entre o número de ocorrências de disseminação de produção científica contábil e o de número de cursos, distribuídos por Dependência Administrativa, com a extração da média aritméti$\mathrm{ca}$, conforme Tabela $9 \boldsymbol{0}$.

Nesse comparativo, observou-se que as Instituições de dependência Estadual apresentaram a maior média aritmética, com cerca de 79 (setenta e nove) ocorrências por IES, seguida da dependência Federal, com uma média de 61 (sessenta e um) registros por Instituição. Novamente, o destaque negativo foi a dependência Municipal, cujo valor obtido representa uma média inferior a 0,2 (dois décimos) registros por Instituição. Observou-se, igualmente, que, ao considerar a média aritmética geral, que é de aproximadamente 19 (dezenove) ocorrências por IES, destacaram-se as Instituições de dependências Estadual e Federal, as quais apresentaram valores três vezes superiores em relação à média geral. Situação semelhante, também, foi apresentada pelas IES que obtiveram Conceito $A$ no ENC 2003. As demais categorias das variáveis Conceito no ENC e Dependência Administrativa apresentaram valores médios inferiores a 50\% (cinqüenta por cento) da média geral das ocorrências de disseminação da produção científica por Instituição.

Por fim, apresenta-se um resumo da distribuição das IES de acordo com o conceito, a Dependência Administrativa e a Situação, conforme se verifica na Tabela $10 \mathbf{0}$.

Esse comparativo permite observar quantas das IES distribuídas por Conceito no ENC e por Dependência Administrativa apresentaram ocorrências de disseminação, bem como a quantidade de Instituições que não evidenciaram registros.

Tabela 9 - Valores médios da distribuição das ocorrências de disseminação de produção científica contábil por Dependência Administrativa, 2004

\begin{tabular}{|c|c|c|c|c|c|}
\hline \multirow{2}{*}{ Descrição } & \multicolumn{4}{|c|}{ Dependência Administrativa } & \multirow{2}{*}{ Total } \\
\hline & Estadual & Federal & Municipal & Privada & \\
\hline Número de ocorrências & 2.206 & 2.270 & 2 & 1.233 & 5.711 \\
\hline Número de cursos & 28 & 37 & 12 & 226 & 303 \\
\hline VALORES MÉDIOS & 78,79 & 61,35 & 0,17 & 5,46 & 18,85 \\
\hline
\end{tabular}

Tabela 10 Distribuição dos cursos da amostra de acordo com o Conceito no ENC 2003, Situação e Dependência Administrativa, 2004

\begin{tabular}{|c|c|c|c|c|c|c|}
\hline \multirow{2}{*}{ Conceito } & \multirow{2}{*}{ Situação } & \multicolumn{4}{|c|}{ Dependência Administrativa } & \multirow{2}{*}{ Tota } \\
\hline & & Estadual & Federal & Municipal & Privada & \\
\hline \multirow{2}{*}{ A } & Não Publica & 6 & 5 & 2 & 29 & 42 \\
\hline & Publica & 8 & 11 & 0 & 12 & 31 \\
\hline Subtotal & & 14 & 16 & 2 & 41 & 73 \\
\hline \multirow{2}{*}{ B } & Não Publica & 5 & 9 & 4 & 28 & 46 \\
\hline & Publica & 1 & 1 & 0 & 9 & 11 \\
\hline Subtotal & & 6 & 10 & 4 & 37 & 57 \\
\hline \multirow{2}{*}{ C } & Não Publica & 7 & 8 & 5 & 105 & 125 \\
\hline & Publica & 1 & 3 & 1 & 43 & 48 \\
\hline Subtotal & & 8 & 11 & 6 & 148 & 173 \\
\hline TOTAL & & 28 & 37 & 12 & 226 & 303 \\
\hline
\end{tabular}




\section{CONCLUSÃO}

Durante este estudo buscou-se identificar, à luz do problema de pesquisa estabelecido, quais as Instituições de Ensino Superior brasileiras que utilizam os Websites institucionais para disseminar o conhecimento acadêmico-científico contábil e a maneira como tais recursos estão sendo utilizados pelas IES no processo de compartilhamento do conhecimento. Para tanto, realizou-se um estudo de campo a partir dos sites das Instituições que ministram o curso de Ciências Contábeis e que satisfizeram aos critérios estabelecidos na delimitação desse trabalho. Concluiu-se que o conhecimento científico contábil está sendo disseminado através dos sites, entretanto, com algumas evidências significativas:

- um elevado percentual das Instituições que atenderam aos critérios determinados para escolha da amostra não apresentou ocorrências, tendo atingido cerca de $70 \%$ (setenta por cento) das IES pesquisadas;

- o volume médio de ocorrências de disseminação científica por IES pode ser considerado baixo, uma vez que não atinge 20 (vinte) ocorrências médias por Instituição. Essa informação confirma a hipótese, a qual afirma que os pesquisadores da área contábil das IES brasileiras exploram pouco a Internet para publicar suas pesquisas. Isso porque, embora não tenham sido realizados testes estatísticos para validação da hipótese, dadas as características do tipo de amostragem utilizado, apenas 90 (noventa) IES apresentaram ocorrências, percentual inferior a 30\% (trinta por cento) daquelas pesquisadas. Além disso, os registros não se vinculam a um número de pesquisadores que atuam no curso e não distinguem o ano de publicação (indicadores de produção científica por docente ou por pesquisador ano a ano, por exemplo). Nesse caso, a média de ocorrências por curso, mesmo considerados tais fatores, reforça a aceitação da hipótese;

- há uma elevada concentração das ocorrências de produção científica disseminada nos sites quando se observam alguns aspectos: o comparativo da distribuição do volume de produção de acordo com a Região evidenciou que as regiões Sudeste, Sul e
Nordeste apresentaram valores elevados em relação às demais. Além disso, o número de UF que não apresentaram evidências de publicação foi elevado, sendo superior a $50 \%$ (cinqüenta por cento);

- as Instituições Públicas (Federais, Estaduais e Municipais somadas) destacaram-se em relação às Instituições Privadas, pois detêm um número de ocorrências próximo a $80 \%$ (oitenta por cento) do total de registros efetuados;

- o número de ocorrências médias de disseminação das Instituições que obtiveram Conceito A no Exame Nacional de Cursos 2003 é maior que o das IES que obtiveram Conceito $B$; situação análoga se apresenta em relação aos Conceitos B e C. Essa informação coincide com a classificação utilizada pelo INEP/MEC, pela qual o Conceito $A$ denota Instituição de qualidade superior, seguida do Conceito $B$, de qualidade média superior e por fim o Conceito $C$, que representa a qualidade média. Conclui-se, nessa situação, que a escolha da amostra, a partir do critério de conceitos médios ou superiores à média no ENC, representou, de fato, um subgrupo típico do universo da pesquisa e confirma a escolha da amostragem não probabilística por tipicidade como um tipo recomendado para o estudo.

Dessa forma, tendo como base o problema de pesquisa, concluiu-se que a maneira como as Instituições de Ensino Superior brasileiras utilizam os Websites institucionais pode ser considerada tímida no que se refere ao acesso à produção acadêmico-científica contábil. Isso porque um elevado número de Instituições não utiliza os Websites como meio de disseminação do conhecimento e as evidências de disseminação apresentam forte concentração sob diversos parâmetros, tanto por Região quanto por Unidade Federativa e por Instituição. Além desses, também apresentaram forte concentração nas IES por Dependência Administrativa, bem como naquelas que obtiveram conceitos mais elevados no Exame Nacional de Cursos 2003.

\section{Referências Bibliográficas}

AMARAL, G., A internet e o compartilhamento da informação científica: o caso da Universidade de Brasília. 1997. 145f. Dissertação (Mestrado em Ciência da Informação) - Departamento de Ciência da Informação e Documentação, Universidade de Brasília, Brasília.

BERNARDES, R. M. Um estudo sobre a demanda de informações em sites web: o caso de uma unidade de pesquisa de uma empresa de P \& D para o agronegócio brasileiro. 2001. 89f. Dissertação (Mestrado Interinstitucional em Administração) - Programa de Pós-Graduação em Administração, Universidade Federal do Rio Grande do Sul/Universidade da Região da Campanha, Bagé.

BLATTMANN, U.; FRAGOSO, G. M. (orgs.). O zapear a informação em bibliotecas e na internet. Belo Horizonte: Autêntica, 2003.

BRASIL. Ministério da Educação. Instituto Nacional de Estudos e Pesquisas Educacionais Anísio Teixeira. Resultado do Exame Nacional de Cursos 2003 por Estado. Microsoft Excel. Quadro de referência de desempenho - ENC2003, Tam. 20,8MB. Acesso em: 04 mar. 2004.

BUENO, W. C. Jornalismo científico no Brasil: os compromissos de uma prática dependente. 1984. 364f. Tese (Doutorado em Comunicação) - Departamento de Jornalismo e Editoração, Escola de Comunicação e Artes, Universidade de São Paulo, São Paulo, 1984. 
COHEN, E. Accountant's guide to the internet. $2^{\text {nd }}$ ed., New York: John Wiley \& Sons, Inc., 2000.

COLBERT, J. L; ALDRIDGE, C. R.; ROSS, M.. Using the internet to access accounting journals: improving research efficiency. In: Journal of Education for Business. mar/apr. 2002, vol. 77 Issue 4, p203, 4p, 1 chart.

Declaração de Berlim sobre acesso livre ao conhecimento nas ciências e humanidades. Versão portuguesa elaborada pelos Serviços de Documentação da Universidade do Minho. Disponível em: <https://repositorium.sdum.uminho.pt/about/declaracao-berlim.pdf $>$. Acesso em 23 mar. 2005.

DODGE, B.. Webquest: uma técnica para aprendizagem na rede internet. Disponível em: <http://www.webquest.futuro.usp.br/artigos/textos_ bernie.html>. Acesso em 13 mar. 2005.

GIL, Antonio Carlos. Métodos e técnicas de pesquisa social. 5. ed., São Paulo: Atlas, 1999.

LAUDON, K. C; LAUDON, J.,Sistemas de informação com internet. Tradução Dalton Conde de Alencar. 4. ed., Rio de Janeiro: LTC Editora, 1999.

Sistemas de informação gerenciais: administrando a empresa digital. Tradução Arlete Simille Marques; revisão técnica Érico Veras Marques; Belmiro João. 5. ed., São Paulo: Prentice Hall, 2004.

LEÓN, A. G.; DÍAZ, A. G., Los sítios Web como estructuras de información: um primer abordaje en los criterios de calidad. Biblios, abril-junio, n. 12, ano 3, Universidad Peruana de Ciencias Aplicadas, Lima, Peru, 2002, p. 1-16.

LÉVY, P., O que é o virtual? Tradução de Paulo Neves. São Paulo: Ed. 34, 1996.

MARCONI, Marina de Andrade; LAKATOS, Eva Maria. Técnicas de pesquisa. 4. ed., rev. ampl. São Paulo: Atlas, 1999.

MARTHE, M., A guerra dos buscadores. Revista Veja. v. 37, n. 47, nov. 2004, 24/11/2004, p. 66-69.

MEADOWS, A. J. Avaliando o desenvolvimento da comunicação eletrônica. In: MUELLER, Suzana Pinheiro Machado; PASSOS, Edilenice Jovelina Lima. (orgs.) Comunicação científica. Brasília: Departamento de Ciência da Informação da Universidade de Brasília, 2000. (Estudos avançados em Ciência da Informação, 1), p. 23-34.

MONTEIRO, S. D.. A organização virtual do conhecimento no ciberespaço. DataGramaZero - Revista de Ciência da Informação. V. 4, n. 6 , dez/03. Disponível em: <http://www.dgz.org.br/dez03/Art_05.htm>. Acesso em 16 ago. 2004.

MUELLER, S. P. M.; PASSOS, E. J.. As questões da comunicação científica e a ciência da informação. In: MUELLER, Suzana Pinheiro Machado; PASSOS, Edilenice Jovelina Lima. (orgs.) Comunicação científica. Brasília: Departamento de Ciência da Informação da Universidade de Brasília, 2000. (Estudos avançados em Ciência da Informação, 1), p. 13-22.

OLIVEIRA, Silvio Luiz de. Tratado de metodologia científica: projetos de pesquisas, TGI, TCC, monografias, dissertações e teses. São Paulo: Pioneira, 1997.

José Renato Sena. Contabilidade e hipertextualidade: um estudo exploratório sobre o uso de websites como meio de disseminação da produção científica contábil por IES brasileiras. Salvador, 2005. Dissertação (Mestrado em Contabilidade) - Centro de PósGraduação e Pesquisa Visconde de Cairu, Fundação Visconde de Cairu, Salvador, 2005. 204p.

RICCIO, E. L.; SAKATA, M G. PeCont: a pesquisa acadêmica contábil no Brasil, TECSI/FEA/USP, São Paulo, 2003. Disponível em <www.tecsi. fea.usp.br/producao $>$. Acesso em: 12 out. 2005.

RODRIGUES, E., Acesso livre ao conhecimento: a mudança do sistema de comunicação da ciência e os profissionais de informação. Cadernos BAD. 1 (2004), 24-35. Lisboa.

RUSSELL, J. M., Tecnologias eletrônicas de comunicação: bônus ou ônus para os cientistas dos países em desenvolvimento? In: MUELLER, Suzana Pinheiro Machado; PASSOS, Edilenice Jovelina Lima. (orgs.) Comunicação científica. Brasília: Departamento de Ciência da Informação da Universidade de Brasília, 2000. (Estudos avançados em Ciência da Informação, 1), p. 35-49.

TAJRA, Sanmya Feitosa. Internet na educação: o professor na era digital. São Paulo: Érica, 2002.

TARGINO, M. G. A região geográfica como fator interveniente na produção de artigos de periódicos científicos. In: MUELLER, Suzana Pinheiro Machado; PASSOS, Edilenice Jovelina Lima. (orgs.) Comunicação científica. Brasília: Departamento de Ciência da Informação da Universidade de Brasília, 2000. (Estudos avançados em Ciência da Informação, 1), p. 51-72.

TEIXEIRA, Adriano Canabarro. Internet e democratização do conhecimento: repensando o processo de exclusão social. 2001, 129f. Dissertação (Mestrado em Educação) - Programa de Pós-Graduação em Educação, Universidade de Passo Fundo, Passo Fundo.

ZAMBONI, L. M., Cientistas, jornalistas e a divulgação científica: subjetividade e heterogeneidade no discurso da divulgação científica. Campinas-SP: Autores Associados, 2001.

ZIEBART, D. A. et al. An introduction to applied professional research for accountants. 2nd ed., New Jersey: Prentice Hall/Upper Saddle River, 2001.

; FELLER, A. L., Teaching applied professional research. University of Illinois at Urbana-Champaign.Disponível em $<$ http:// www.business.uiuc.edu/ziebart/appliedresearch/ research.htm>. Acesso em: 12 out. 2004.

NOTA - Endereço dos autores

Universidade Federal da Bahia

Faculdade de Ciências Contábeis

Praça da Piedade, 06 - Centro

Salvador - BA

40070-010
Universidade do Estado da Bahia

Rua Silveira Martins, 2555 - Cabula

Salvador-BA

41195-001 